\title{
GLICERINA NA ALIMENTAÇÃO DE BOVINOS
}

\author{
PAIVA, Pablo Gomes de ${ }^{1}$; \\ RENNÓ, Francisco Palma ${ }^{2}$; \\ DEL VALLE, Tiago Antônio ${ }^{3}$; \\ JESUS, Elmeson Ferreira de ${ }^{1}$; \\ SANTOS, Fernanda Carolina Ramos ${ }^{4}$; \\ COSTA, Artur Gabriel Brao Vila Boas ${ }^{5}$; \\ CABRAL, Guilherme Fonseca ${ }^{6}$; \\ ALMEIDA, Gustavo Ferreira de ${ }^{7}$.
}

${ }^{1}$ Doutorando/Departamento de Zootecnia, FCAV/UNESP, Jaboticabal-SP; ${ }^{2}$ Professor/Departamento de Nutrição e Produção Animal, FMVZ/USP, Pirassununga-SP; ${ }^{3}$ Doutorando/Departamento de Nutrição e Produção Animal, FMVZ/USP, Pirassununga-SP; ${ }^{4}$ Graduanda em Medicina Veterinária, FMVZ/USP, São Paulo-SP; ${ }^{5}$ Graduando em Medicina Veterinária, FMVZ/USP, São Paulo-SP; ${ }^{6}$ Graduando em Zootecnia, FZEA/USP, Pirassununga, SP; ${ }^{7}$ Mestre/Departamento de Nutrição e Produção Animal, FMVZ/USP, Pirassununga-SP.

\section{RESUMO}

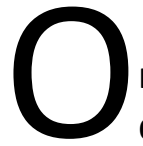
aumento na demanda de energia, impulsionado pelo crescimento da população mundial, tem levado a busca por novas fontes de energia. Os biocombustíveis têm se destacado como fonte energética complementar ou substitutiva, entre as quais o biodiesel assume grande relevância, pois além de fonte renovável é considerado ecológico, biodegradável, atóxico, livre de enxofre e compostos aromáticos. Contudo, para que a produção de biodiesel seja biológica e economicamente viável, é necessário dar destino adequado aos coprodutos gerados durante sua obtenção. A glicerina, principal coproduto gerado durante a produção de biodiesel tem sido considerada potencial fonte energética na alimentação animal, principalmente em substituição ao milho. A inclusão de glicerina na dieta de ruminantes tende a aumentar a produção ruminal de propionato e butirato, e diminuir a de acetato, levando a uma redução na relação acetato: propionato e consequente aumento na eficiência de uso da energia da dieta. No entanto, sua influência sobre o consumo tem sido o principal fator limitante à sua inclusão como macroingrediente nas dietas. Assim, realizou-se uma revisão no que se refere à utilização da glicerina na alimentação e seu efeito sobre o desempenho de bovinos de corte e de leite.

Palavras-chave: Biodiesel. Coprodutos. Desempenho. Glicerol. 


\section{INTRODUÇÃO}

O crescimento da população mundial aliado ao aumento no poder aquisitivo, o desenvolvimento industrial e agrário de muitas regiões, estimularam o aumento no consumo de energia, representado principalmente pelo petróleo. No entanto, essa matriz energética é fonte esgotável e altamente poluente (STORCK BIODIESEL, 2008).

A utilização de biocombustíveis vem se mostrando como potencial fonte energética complementar ou substitutiva, entre as quais o biodiesel vem ganhando destaque, pois além de ser fonte renovável de energia, é considerado ecológico, biodegradável, atóxico, livre de enxofre e compostos aromáticos (ABDALLA et al., 2008). Essas características possibilitam a redução substancial das emissões de hidrocarbonetos e monóxidos de carbono, minimizando o impacto ambiental (STORCK BIODIESEL, 2008). Contudo, para que a produção de biodiesel seja biológica e economicamente viável, é necessário dar destino adequado aos coprodutos gerados durante a obtenção do biodiesel.

A partir dos grãos de oleaginosos como a soja, algodão, girassol, entre outros, a agroindústria obtém além do biodiesel, coprodutos de qualidade nutricional que podem ser utilizados na alimentação de bovinos. Esses alimentos são as tortas e a glicerina, sendo esta última, o principal coproduto obtido a partir da produção do biodiesel (ABDALLA et al., 2008).

A glicerina tem sido considerada potencial ingrediente energético, podendo ser incluída na alimentação de ruminantes em substituição ao milho (DONKIN et al., 2009; PARSONS et al., 2009; TERRÉ et al., 2011). Uma característica importante da glicerina é a capacidade do glicerol em ser transformado a ácidos graxos de cadeia curta no rúmen, principalmente em ácido propiônico (BERGNER et al., 1995), promovendo melhor aporte energético aos animais.

Porém, como a composição e qualidade da glicerina disponível no mercado variam devido à presença de possíveis contaminantes, oriundos do processo de sua obtenção (transesterificação), pode haver inconvenientes quanto ao seu uso na alimentação de bovinos quando utilizada como macroingrediente nas dietas. Ainda, como os custos com alimentação em sistemas intensivos de produção de bovinos chegam a mais de $60 \%$ do custo 
da atividade (CEPEA, 2015), a busca por alimentos alternativos que possibilitem redução nos custos com alimentação e mantenham os índices produtivos faz se necessária. Assim, realizou-se uma revisão no que se refere à utilização da glicerina na alimentação e seu efeito sobre o desempenho de bovinos de corte e de leite.

\section{BIODIESEL E GLICERINA}

O biodiesel pode ser definido como produto obtido através da transformação química de ácidos graxos de cadeia longa, oriundo de lipídios orgânicos renováveis, óleo ou gordura (vegetal ou animal) por adição de álcool (metanol ou etanol) na presença de catalisador ( $\mathrm{NaOH}$ ou $\mathrm{KOH})$, para utilização em motores diesel (UNIVERSIDADE DE AÇORES, 2008).

No Brasil, diversas fontes são utilizadas para produção de biodiesel (Figura 1), dentre as quais se destacam o óleo de soja e a gordura bovina, que correspondem respectivamente a 73,09 e $21,94 \%$ das fontes utilizadas para produção. O Brasil é o terceiro maior produtor mundial de biodiesel, com uma produção mensal de $347.769 \mathrm{~m}^{3}$ e capacidade autorizada de $643.515 \mathrm{~m}^{3}$. Desde novembro de 2014 o óleo diesel comercializado em todo o território nacional contém 7\% de biodiesel (ANP, 2015), acarretando em aumento na produção de biodiesel e, consequentemente, aumento na oferta de glicerina, principal coproduto da produção de biodiesel.

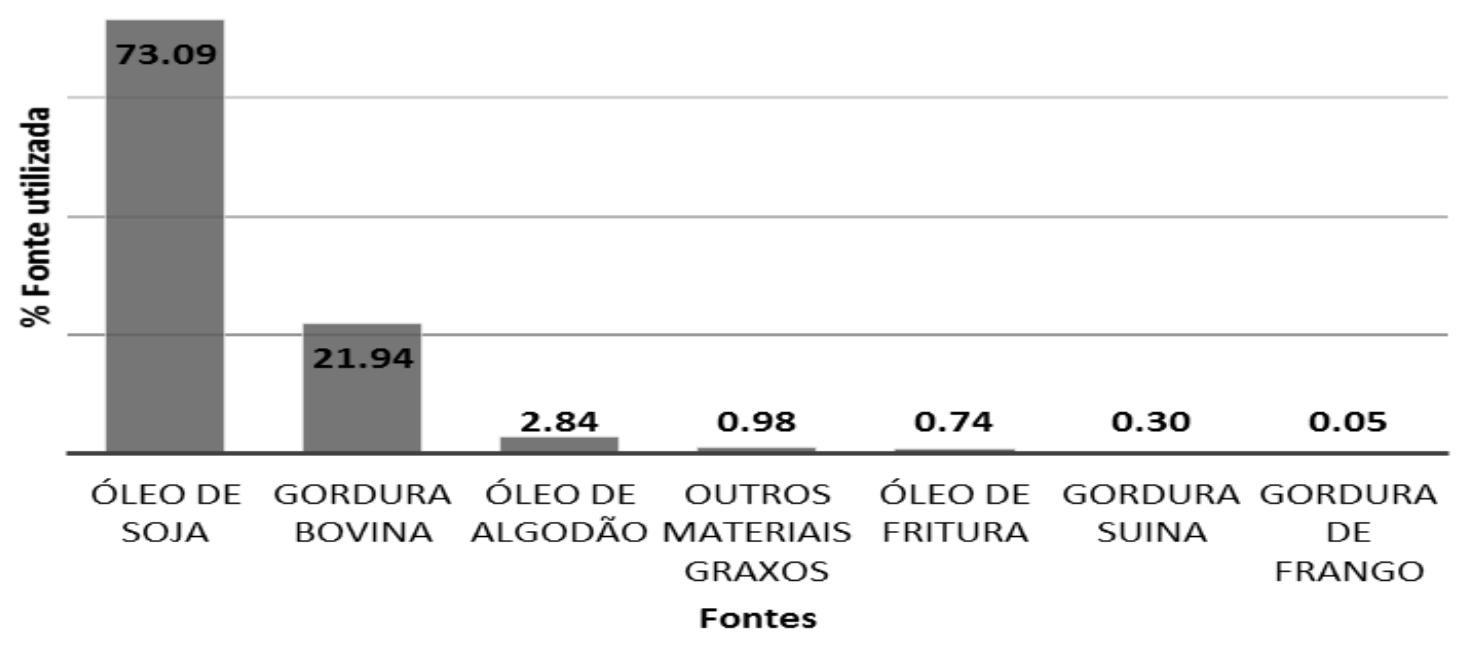

Figura 1 - Perfil das fontes utilizadas na produção de biodiesel no Brasil (Adaptado de ANP, 2015). 
O glicerol (1, 2, 3 propanotriol ou glicerina) foi isolado pela primeira vez pelo químico sueco Carl Wilhelm Scheele, em 1779, durante o processo de saponificação do azeite de oliva. No entanto, já em 1858, Pauster observou sua formação como subproduto da fermentação alcoólica, em concentrações de 2,5-3,6\% do conteúdo de etanol, podendo ser o glicerol o segundo maior produto formado durante a fermentação alcoólica (TOSETTO; ANDRIETTA, 2003).

O termo glicerol é aplicado ao composto puro (1, 2, 3 propanotriol), enquanto o termo glicerina é usado para descrever os compostos comerciais que contém glicerol. Diversos tipos e designações de glicerina estão disponíveis comercialmente, diferindo quanto ao teor de glicerol, álcool, catalizadores, ácidos graxos, sabões, cor e odor (MOTA et al., 2009).

A glicerina apresenta diversos destinos conhecidos, sendo utilizada na confecção de produtos na indústria cosmética, farmacêutica, têxtil e alimentícia, no entanto, sua principal função na maioria dos casos é como umectante (substância para reter umidade). A glicerina possui ainda como característica ser altamente estável sob condições típicas de armazenamento, compatível com muitos outros materiais químicos, não tóxica e não irritante em seus mais variados usos, além de não possuir efeitos ambientais negativos (ARRUDA et al., 2007).

A glicerina é obtida durante a produção do biodiesel através da reação de óleo vegetal ou gordura animal com álcool anidro (geralmente metanol e/ou, às vezes, etanol) (DONKIN, 2008). Durante o processo de transesterificação, o óleo vegetal reage com álcool (metanol ou etanol) na presença de catalisador (hidróxido de sódio ou potássio), resultando em éster monoalquilado (biodiesel) e seu principal coproduto, a glicerina (PLÁ, 2002). Em seguida, por diferença de densidade, ocorre a decantação, permitindo assim a separação do biodiesel (SOUZA, 2006), que com a remoção da glicerina torna-se mais fluido pela redução da viscosidade (VISCARDI, 2005). O rendimento do processo de produção do biodiesel é afetado pela temperatura de reação, tipo e concentração do catalisador e razão molar álcool/óleo vegetal (ENCIMAR et al., 2002). De acordo com Dasari et al. (2005), para cada $90 \mathrm{~m}^{3}$ de 
biodiesel produzidos durante o processo de transesterificação de óleos vegetais, $10 \mathrm{~m}^{3}$ de glicerina são gerados.

Segundo Oliveira et al. (2011), na indústria podem ser obtidas quatro tipos de glicerina: glicerina bruta - contém baixos níveis de glicerol (40 a 70\%) e elevados níveis de catalizadores, álcool, água, ácidos graxos e sabões, com pH normalmente elevado (12), sendo obtida após separação do biodiesel; glicerina bruta "loira" - atualmente é o principal tipo de glicerina obtida na indústria do biodiesel e possui de 75 a 90\% de glicerol, é a glicerina bruta após sofrer tratamento ácido, seguido da remoção dos ácidos graxos e sabões, sendo o restante composto por água, sais e metanol, apresentando pH entre 5 e 6; glicerina grau farmacêutico (grau USP) - contém mais que 99\% de glicerol, é amplamente utilizada nos setores de cosméticos, higiene pessoal, medicamentos e fumo, é obtida da glicerina bruta loira após ser submetida à bidestilação a vácuo e tratamento com absorventes; e a glicerina grau alimentício (food grade) - completamente isenta de metanol.

Mesmo a glicerina purificada sendo um composto de alto valor comercial do ponto de vista industrial, o processo de purificação pode ser inviável economicamente, considerando a elevada quantidade de glicerina produzida atualmente no Brasil. Assim, o uso da glicerina bruta na alimentação animal, particularmente para ruminantes, pode ser uma maneira de aumentar a eficiência biológica e econômica da produção de biodiesel (ZACARONI, 2010).

\section{GLICERINA E ALIMENTAÇÃO ANIMAL}

Glicerina é o nome comercial de um líquido viscoso, incolor, inodoro, higroscópico e com sabor adocicado, quimicamente definido como glicerol (1,2,3 propanotriol) (ARRUDA et al., 2007), tem seu uso reconhecido e é considerada um alimento seguro, porém, atenção deve ser dada aos contaminantes presentes na forma bruta, principalmente nos níveis de metanol, que segundo a Food and Droug Administration (FDA, 2014) não deve ultrapassar $150 \mathrm{mg} / \mathrm{kg}$.

Em função, do aumento na oferta de glicerina, e do seu potencial como macroingrediente na dieta de animais, o Ministério da Agricultura, Pecuária e Abastecimento (MAPA) regularizou 
em outubro de 2010 o uso da glicerina bruta. A partir desse momento o produto deve atender um padrão mínimo de qualidade para utilização na alimentação animal: com no mínimo $80 \%$ de glicerol, máximo de $13 \%$ de umidade, máximo de $150 \mathrm{mg} / \mathrm{kg}$ de metanol, sódio e matéria mineral com valor máximo garantido pelo fabricante, o que pode variar em função do processo produtivo. Destaca-se ainda, a proibição do uso de glicerina proveniente da gordura animal na alimentação de ruminantes devido ao risco de ocorrência de doenças priônicas. As glicerinas oriundas de óleos de mamona e de pinhão manso também estão desautorizadas em função do risco da presença de contaminantes (OLIVEIRA et al., 2011).

Mesmo com a padronização mínima para utilização da glicerina na alimentação animal, ainda é grande a variação principalmente quanto ao teor de glicerol, umidade, sódio e lipídios totais na glicerina oriunda de diferentes regiões do Brasil (Tabela 1).

Tabela 1 - Composição da glicerina de indústrias de biodiesel no Brasil.

\begin{tabular}{ccccc}
\hline \multirow{2}{*}{ Origem } & \multirow{2}{*}{$\mathrm{N}^{*}$} & \multicolumn{3}{c}{ Composição Média \% } \\
\cline { 3 - 5 } & & Glicerol & Umidade & Extrato Etéreo \\
\hline \multirow{2}{*}{ Centro-Oeste } & 8 & 82,1 & 12,4 & 0,5 \\
& 3 & 73,1 & 18,1 & 0,1 \\
\hline Sul & 3 & 75,8 & 11,6 & 4,7 \\
& 1 & 61,6 & 26,6 & 0,0 \\
\hline Sudeste & 1 & 61,0 & 1,3 & 27,1 \\
Nordeste & 2 & 59,4 & 12,1 & 19,3 \\
\hline
\end{tabular}

* Número de amostras analisadas (glicerina a base de óleo de soja ou algodão).

(Adaptado de OLIVEIRA et al., 2013).

\section{Metabolismo do glicerol no rúmen}

Estudos in vivo, avaliando os efeitos da glicerina bruta sobre os parâmetros ruminais em bovinos são escassos. A literatura nos traz, no entanto, relatos dos efeitos ruminais da utilização do glicerol, seu principal componente, responsável por 80 a $90 \%$ da sua composição (KERR et al., 2009). 
O glicerol é importante precursor gliconeogênico amplamente conhecido por seu poder de atuar em diferentes etapas do metabolismo da glicose (LENG, 1970). Segundo Krehbiel (2008), do glicerol consumido, 13\% desaparece do rúmen acompanhando a ingesta, 44\% pela fermentação e $43 \%$ pela absorção através da parede ruminal. O glicerol pode ser convertido em propionato no rúmen através da fermentação microbiana e utilizado na gliconeogênese hepática (KREBS; LUND, 1966). O glicerol absorvido na parede ruminal, no fígado pela ação da enzima glicerol quinase, juntamente com ATP, é convertido em glicerol3-fosfato e ADP para ser utilizado na glicólise ou na gliconeogênese, dependendo da condição metabólica do animal (KREHBIEL, 2008).

Remond et al. (1993) afirmam que do glicerol ingerido, 39 a 69\% é fermentado a ácidos graxos de cadeia curta (AGCC) no rúmen de animais adaptados. No rúmen, o glicerol é rapidamente fermentado, levando ao aumento na produção total de AGCC, com alteração da relação acetato:propionato, quando este é suplementado (ABUGHAZALEH et al., 2010). Segundo Bergner et al. (1995) em seis horas mais de $90 \%$ do glicerol desaparece do rúmen, quando este está sendo utilizado em substituição de 15 a $25 \%$ do amido da dieta. Trabue et al. (2007), sugerem que $80 \%$ do glicerol desaparece após 24 horas de incubação in vitro.

Usando radioisótopos, Bergner et al. (1995) constataram que a maior parte do carbono oriundo do glicerol é utilizada na síntese de propionato e, apenas $11 \%$ na síntese de $\mathrm{CO}_{2}$, enquanto que a presença deste como metano, acido lático e acético produzidos é muito baixa, não sendo identificados neste estudo. Estes autores relatam ainda uma redução da incorporação de nitrogênio na proteína microbiana com aumento na suplementação de glicerol.

Quanto à alteração da proporção dos AGCC produzidos, pode-se dizer que a suplementação com glicerol leva ao aumento da proporção molar de propionato e butirato, com redução da proporção de acetato (WANG et al., 2009). Mach et al. (2009), entretanto, relataram que a utilização de $12 \%$ da matéria seca de glicerina bruta ( $86 \%$ de glicerol) na dieta de bovinos de corte não alterou a proporção dos AGCC produzidos no rúmen.

Rico et al. (2012), em estudo in vitro, avaliaram a substituição de milho por glicerol desidratado, e observaram uma melhora da digestibilidade aparente da fibra em detergente 
neutro, sem alteração da síntese de proteína microbiana. Os autores recomendaram que a inclusão de até $8 \%$ da matéria seca pode ser utilizada, sem prejudicar a fermentação ruminal e a digestibilidade da matéria seca e nutrientes.

Boyd et al. (2013), trabalhando com vacas no terço inicial de lactação e produção de leite de $38 \mathrm{~kg} /$ dia, suplementadas com 0, 200 e 400 gramas de glicerol por dia, observaram efeitos no rúmen semelhantes aos relatados por Wang et al. (2009). Não foram observadas diferenças no pH e na concentração de amônia ruminal. As proporções molares de acetato, e a relação acetato:propionato reduziram, enquanto que a concentração de propionato, butirato e valerato aumentaram com o aumento na suplementação de glicerol. Ainda, segundo estes autores não foram observados efeitos da suplementação sobre o consumo, digestibilidade da matéria seca e nutrientes neste estudo. Lee et al. (2011), em estudos in vitro, relataram que a adição de glicerol ao milho ou alfafa, aumentou a produção de propionato e reduziu a relação acetato: propionato, sem afetar a produção de butirato e AGCC em 24 horas de incubação. A suplementação de glicerol leva ainda a redução da produção de metano por unidade de energia digestível, o que indica melhoria na eficiência energética.

Segundo Carvalho et al. (2011), vacas lactantes recebendo dieta com inclusão de $10,8 \%$ da matéria seca de glicerol não apresentaram diferenças no consumo de matéria seca e aumentaram as proporções de propionato $(22,7$ e $28,6 \%)$ e butirato $(11,5$ e $15,3 \%)$ ruminal, e consequentemente reduziram a relação acetato:propionato $(2,76$ e 1,88$)$ para dietas controle e glicerol, respectivamente. Wang et al. (2009) observaram que a suplementação com doses crescentes de glicerina (0,100, 200 e 300 g/dia; 99\% de glicerol) alterou o padrão de fermentação ruminal, com aumento linear na produção total de AGCC (93,40 a 99,61 $\mathrm{mM})$, na proporção molar de propionato $(16,31 \mathrm{a} 19,08 \mathrm{~mol} / 100 \mathrm{~mol})$ e butirato $(8,27 \mathrm{a}$ $11,35 \mathrm{~mol} / 100 \mathrm{~mol})$, refletindo em redução da relação acetato:propionato $(4,56$ à 3,64$)$ à medida que se incluiu glicerina na dieta.

O glicerol pode ainda atuar sobre a degradabilidade da fração protéica. Paggi et al. (1999) relataram inibição de $20 \%$ da atividade proteolítica quando o glicerol foi utilizado, em diferentes dietas basais. Segundo Ling e Armstead (1995), isso pode acarretar em efeitos 
positivos, uma vez que a degradação protéica ruminal reduz a eficiência de utilização da proteína em ruminantes.

A aceleração do processo fermentativo pode estar diretamente relacionada à alteração das populações microbianas no rúmen. Roger et al. (1992) relataram que a adição de $5 \%$ de glicerol inibe o crescimento e a atividade celulolítica de bactérias e fungos in vitro. Paggi et al. (2004), também relataram redução da atividade celulolítica quando a concentração de glicerol sobe de 50 para 300 mM. Roger et al. (1992) associaram esta redução da atividade celulolítica à diminuição no crescimento, adesão e à inibição das populações microbianas. Porém, o mecanismo pelo qual esta inibição ocorre ainda não está completamente elucidado.

Abughazaleh et al. (2010) avaliaram a substituição de milho por glicerina (99,5\% glicerol) em experimento in vitro. Os autores relataram aumento na concentração de acetato a partir de $30 \%$ de substituição e aumento no propionato na dieta com $45 \%$ de substituição. Ainda, as concentrações de DNA de Butyrivibrio fibrisolvens e Selenomonas ruminantium foram reduzidas nas dietas com 30 e $45 \%$ de substituição. Ruminococcus albus e Succinivibrio dextrinosolvens não foram alterados pelas dietas experimentais. Das quatro bactérias testadas neste estudo, duas têm importante atividade celulolítica (B. fibrisolvens, $R$. albus) enquanto outras duas são importantes na degradação de amido (S. ruminantium, $S$. dextrinosolvens) no rúmen (TAJIMA et al., 2001; RUSSELL, 2002). De acordo com Hobson e Mann (1961), as bactérias do gênero Selenomonas são as mais importantes no metabolismo do glicerol. Abughazaleh et al. (2010) concluíram que dietas com substituição de até 15\% não tem efeito sobre a fermentação ruminal. No entanto, altas concentrações de glicerol levam a efeitos adversos sobre as bactérias ruminais e a produção de acetato. Segundo Roger et al. (1992), em baixas concentrações (0,1 a 1\%), o glicerol não tem efeito sobre o crescimento, adesão e atividade celulolítica de duas populações microbianas (Ruminococcus flavefaciens e Fibrobacter succinogenes); no entanto, numa concentração de $5 \%$ há inibição do crescimento e da atividade celulolítica, sem afeitos sobre a adesão.

No processo de obtenção da glicerina são geradas algumas substâncias que podem comprometer a saúde e o desempenho animal. O metanol, talvez a mais importante dessas 
substâncias, tem recebido grande atenção, especialmente pela produção de acido fórmico durante sua metabolização hepática. Leão et al. (2012) estudaram alterações anatomopatológicas e não conseguiram estabelecer qualquer relação entre lesões hepáticas, ruminais, renais ou intestinais, com a suplementação de glicerina até $24 \%$ da matéria seca da dieta.

A suplementação com glicerina altera a proporção de AGCC produzidos no rúmen, com aumento na produção de propionato e consequente redução da relação acetato: propionato (BOYD et al., 2013; CARVALHO et al., 2011; WANG et al., 2009), o que leva a redução de hidrogênio disponível no rúmen para produção de metano e aumento na eficiência de uso da energia da dieta. Com isso a produção de metano, bem como as estratégias nutricionais de mitigação da sua emissão tem recebido especial atenção da pesquisa em nutrição animal; pois, os efeitos ambientais da emissão e a ineficiência energética decorrente da produção ruminal de metano, justificam essa busca (JOHNSON; JOHNSON, 1995).

Existem muitos fatores nutricionais e do animal que podem interferir na produção de metano. A ingestão de matéria seca, o tipo de carboidrato utilizado, a adição de lipídeos, o processamento da forragem e a manipulação da fermentação ruminal são, segundo Johnson e Johnson (1995), os fatores mais importantes. A produção de metano é, no entanto, fisiologicamente importante para a manutenção da pressão de $\mathrm{H}_{2}$ reduzida, permitindo a reoxidação do NADH e maior rendimento de acetato e ATP.

De acordo com Stradiotti Júnior et al. (2004), no ecossistema ruminal há relação inversa entre a produção de metano e de propionato. O mecanismo pelo qual se justifica essa relação consiste no direcionamento dos hidrogênios e carbonos (coprodutos da produção de acetato) para produção de propionato, que não estariam disponíveis para metanogênese. Johnson e Johnson (1995) afirmaram que especialmente a relação acetato:propionato é importante na produção de metano. Segundo estes autores, uma relação menor que 0,5 inibe a produção de metano por redução do substrato para o crescimento das bactérias metanogênicas. Por outro lado, se o carboidrato é fermentado a acetato e não a propionato, até $33 \%$ da energia pode ser perdida na forma de metano. Como a relação 
acetato:propionato no rúmen tende a variar de 0,9 a 4,0, in vivo, a produção de metano é sempre presente e importante.

Conforme discutido anteriormente neste capítulo e, considerando a capacidade da glicerina de alterar o perfil dos AGCC produzidos no rúmen, com redução da relação acetato:propionato (BOYD et al., 2013; CARVALHO et al., 2011; LEE et al., 2011; WANG et al., 2009), o efeito mitigador da glicerina é promissor. Os trabalhos, no entanto, utilizam técnicas ainda pouco sensíveis, dificultando o estabelecimento dos reais efeitos dos diferentes níveis de suplementação de glicerina bruta sobre a produção de metano ruminal. Ávila et al. (2011), estudaram o efeito de teores crescentes de glicerina contendo 99,5\% de glicerol $(0,7,14$ e $21 \%$ MS) sobre a fermentação ruminal e produção de metano, e observaram que, apesar da redução das proporções molares de acetato e butirato, e do aumento da concentração de propionato, a produção de metano não foi afetada. A taxa de fermentação ruminal in vitro e a produção de metano originada do glicerol foi objetivo do estudo de Lee et al. (2011). Estes autores usaram os tempos de coleta do líquido ruminal de 0, 3, 6, 12, 24 e 48 horas e obtiveram taxa de produção de gás de 0,051/hora. A adição de glicerol reduziu a produção de metano e não alterou a produção total de AGCC, em 24 horas. Estes resultados sugerem aumento na eficiência do uso da energia quando as dietas foram suplementadas com glicerol.

Silva (2011), também avaliou a produção de metano in vitro em dietas suplementadas com 0, 15 e 30\% de glicerina bruta na matéria seca. A produção de metano aumentou linearmente com o aumento da suplementação de glicerina. O autor cita, assim como Santos et al. (2011), que altas concentrações de glicerina, substituindo até $75 \%$ do amido da dieta, tem grande capacidade de aumentar a produção de metano.

Paschoaloto (2012) avaliou a inclusão da glicerina em dietas contendo silagem de milho, feno de Tifton 85 e cana-de-açúcar hidrolisada na alimentação de bovinos de corte confinados e seus efeitos sobre os parâmetros ruminais e a produção de gases. Não foi detectado efeito para a produção de metano entre as dietas, apenas a produção de $\mathrm{CO}_{2}$ foi maior para o tratamento cana-de-açúcar hidrolisada com glicerina (51,18 mL/g MS). Já Van Cleef (2012) avaliou a produção de metano e $\mathrm{CO}_{2}$, além das bactérias aderidas a fração 
sólida, em dietas suplementadas com diferentes teores de glicerina bruta. A inclusão de $30 \%$ de glicerina deprimiu a digestibilidade e degradabilidade da fibra, reduziu a produção de metano e $\mathrm{CO}_{2}$ e interferiu negativamente na produção de bactérias sólido-aderidas, não alterando as variáveis de desempenho e características da carcaça avaliadas.

\section{Desempenho de Bovinos Alimentados com Glicerina}

Inicialmente o uso de glicerol em ruminantes foi proposto como tratamento para cetose em vacas leiteiras. Johnson (1954) relatou que a utilização de glicerol via oral foi mais eficiente no tratamento da cetose que a mesma quantidade de propilenoglicol. Mais tarde a glicerina passou a ser utilizada na prevenção e não apenas no tratamento da cetose. Vacas da raça Holandês recebendo $374 \mathrm{~g} /$ dia de glicerol perderam menos peso e permaneceram mais tempo em balanço energético positivo que aquelas recebendo 0 ou $174 \mathrm{~g}$ de glicerol, ou 174 g de propilenoglicol, durante as oito primeiras semanas de lactação (FISHER et al., 1973).

Atualmente, em ruminantes devido à presença do glicerol, a glicerina tem se caracterizado como potencial e promissora fonte energética, principalmente em substituição a fontes ricas em amido (DONKIN, 2008; DONKIN et al., 2009; TERRÉ et al., 2011). Em dietas de alto concentrado, o intervalo para inclusão da glicerina estaria entre 10 a 15\% na matéria seca (MS) da dieta (CARVALHO et al., 2011; DONKIN et al., 2009; MACH et al., 2009; TERRÉ et al., 2011).

Schröder e Südekum (1999) avaliaram a inclusão de 15\% de glicerina de diferentes purezas (63,3; 85,3 e 99,8\% de glicerol) em substituição ao amido na dieta de novilhos, e não observaram efeitos sobre o consumo de matéria seca $(13,4 \mathrm{~kg} / \mathrm{dia})$ e digestibilidade dos nutrientes.

A inclusão de glicerina na dieta de novilhas $(0,2,4,8,12$ e 16\% MS) a base de milho floculado e $6 \%$ de feno de alfafa reduziu linearmente o consumo de matéria seca (CMS) e propiciou efeito quadrático para ganho de peso diário, sendo o maior ganho $(1,34 \mathrm{~kg})$ alcançado com $2 \%$ de glicerina na dieta (PARSONS et al., 2009). Porém, estes autores destacaram que a inclusão de glicerina na dieta de animais em terminação melhora o ganho de peso e eficiência alimentar, principalmente quando incluída até $8 \%$ da matéria seca. 
Mach et al. (2009) avaliaram a inclusão de glicerina em até $12 \%$ da MS (86\% de glicerol) em dietas de alto concentrado para tourinhos, e não observaram efeito sobre o CMS e ganho de peso diário, com média de 8,27 e 1,35 kg/dia, respectivamente. Os autores ainda estimaram a concentração de energia metabolizável da glicerina em tourinhos da raça Holandês sendo de 3,47 Mcal/kg de MS. Gunn et al. (2011) trabalhando com animais F1 Angus desmamados precocemente, não observaram diferença no CMS, e relataram maior ganho de peso diário $(1,33 \mathrm{~kg})$ e área de olho de lombo em animais alimentados com dietas contendo $15 \%$ de glicerina (90 \% de glicerol) mais 30\% de grãos secos de destilaria em substituição ao milho.

No Brasil, alguns trabalhos têm avaliado a inclusão de glicerina na dieta de bovinos em terminação. A Tabela 2 apresenta uma compilação dos diferentes trabalhos com inclusão de glicerina à dieta de bovinos em terminação. D’Aurea (2010) utilizando inclusões de 0, 10 e $20 \%$ de glicerina ( $83 \%$ de glicerol) a dietas de alto concentrado ( $70 \%$ concentrado na MS) para novilhas Nelore em terminação, relatou redução no CMS com inclusão de $20 \%$ de glicerina a dieta, porém, sem alterar o ganho de peso diário, que foi maior com uso de glicerina (1,33 kg/dia) comparado a dieta controle (1,23 kg/dia). Carvalho (2011) avaliou a inclusão crescente de glicerina (0, 6, 12 e 18\% de glicerina na MS; 83\% glicerol) em substituição ao milho em dietas de alto concentrado, e não observou diferença no ganho de peso diário (1,82 kg/dia), com tendência de aumento na área de olho de lombo e aumento linear no rendimento de carcaça quente. Van Cleef et al. (2014) com inclusões de 0, 7,5, 15, 22,5 e $30 \%$ de glicerina ( $86 \%$ de glicerol) na dieta de novilhos Nelore terminados com dietas de alto concentrado, não encontraram diferença no CMS e ganho de peso diário, que apresentaram médias de 8,36 e 1,62 kg/dia, respectivamente. Fávaro (2010) também não observou diferença no CMS com inclusões de 0, 5, 10, 15 e 20\% de glicerina na MS da dieta (83\% de glicerol) com relação volumoso:concentrado de 40:60. 
Tabela 2 - Consumo de matéria seca (CMS), ganho médio diário (GMD) e eficiência alimentar (EA) de bovinos de corte terminados em confinamento, com inclusão de glicerina às dietas, no Brasil.

\begin{tabular}{|c|c|c|c|c|}
\hline Fontes & Tratamento & CMS (kg/dia) & GMD (kg/dia) & $\overline{E A}(\mathrm{~kg} / \mathrm{kg})$ \\
\hline \multirow{3}{*}{ D’Aurea (2010) } & $0 \%$ Glicerina & 8,70 & $1,23^{*}$ & 0,14 \\
\hline & 10\% Glicerina & 9,71 & 1,38 & 0,14 \\
\hline & 20\% Glicerina & $8,04^{*}$ & 1,28 & 0,15 \\
\hline \multirow{4}{*}{ Carvalho (2011) } & 0\% Glicerina & 11,81 & 1,75 & 0,14 \\
\hline & $6 \%$ Glicerina & 11,96 & 1,87 & 0,15 \\
\hline & 12\% Glicerina & 11,89 & 1,88 & 0,15 \\
\hline & 18\% Glicerina & 11,07 & 1,80 & 0,16 \\
\hline \multirow{5}{*}{ Van Cleef et al. (2014) } & 0\% Glicerina & 8,96 & 1,54 & 0,17 \\
\hline & 7,5\% Glicerina & 7,81 & 1,69 & 0,22 \\
\hline & 15\% Glicerina & 8,49 & 1,75 & 0,21 \\
\hline & $22,5 \%$ Glicerina & 8,75 & 1,70 & 0,20 \\
\hline & 30\% Glicerina & 7,79 & 1,44 & 0,19 \\
\hline \multirow{6}{*}{ Paschoaloto (2012) } & Cana hidrolisada & 6,99 & --- & --- \\
\hline & Cana $+10 \%$ glicerina & 6,52 & --- & --- \\
\hline & Feno Tifton 85 & 6,72 & --- & --- \\
\hline & Feno+10\% glicerina & 6,53 & --- & --- \\
\hline & Silagem de Milho & $9,06 *$ & --- & --- \\
\hline & Silagem+10\%glicerina & $8,67 *$ & --- & --- \\
\hline
\end{tabular}

*Difere dos demais tratamentos.

(CARVALHO, 2011; D’AUREA, 2010; PASCHOALOTO, 2012; VAN CLEEF et al., 2014).

Ao avaliar a inclusão ou não de $10 \%$ glicerina ( $83 \%$ glicerol) na dieta de bovinos associada a diferentes volumosos, em relação volumoso:concentrado 50:50, Paschoaloto (2012) relatou redução no CMS para os tratamentos cana-de-açúcar hidrolisada, cana-de-açúcar hidrolisada+glicerina, feno de Tifton 85 e feno de Tifton 85+glicerina, quando comparados à silagem de milho ou silagem de milho+glicerina, com medias de 9,06 e 8,67 kg/dia, respectivamente. Segundo o autor este resultado pode ser explicado pelo alto teor de FDN nas dietas a base de cana-açúcar hidrolisada e feno de Tifton 85 , implicando maior tempo de retenção do material no rúmen, pois a degradação da matéria seca foi menor quando comparado às dietas com silagem de milho e silagem de milho+glicerina, levando ao maior tempo para sua degradação. 
Em bovinos de leite a utilização de glicerina na alimentação tem sido avaliada em diferentes estudos. Donkin et al. (2009) avaliaram quantidades crescentes de glicerina 0, 5, 10 e 15\% na MS da dieta (99,5\% glicerol) e não observaram diferença para CMS e produção de leite, com média de 24,3 e 36,9 kg/dia, respectivamente. Ainda, de acordo com esses autores, vacas alimentadas com dietas contendo 10 e 15\% de glicerol ganharam mais peso que aquelas sem ou com $5 \%$ de glicerina. Assim, a glicerina pode ser incluída na dieta em substituição ao milho em até $15 \%$ da MS sem efeitos adversos sobre a produção e composição do leite.

Berry (2007) avaliou o uso da glicerina em dietas para vacas leiteiras, através dos seguintes tratamentos: sem glicerina+37\% de carboidratos não fibrosos (CNF), $5 \%$ de glicerina+37\% de CNF, $10 \%$ de glicerina+37\% de CNF e $10 \%$ de glicerina+42\% de CNF, e não encontrou diferença no CMS e produção de leite, com médias de 23,9 e $39,5 \mathrm{~kg} /$ dia, respectivamente. Ainda assim, a inclusão de glicerina nas dietas aumentou o consumo em $2 \mathrm{~kg}$ no tratamento com $10 \%$ de glicerina+42\% de CNF em comparação ao controle ( $0 \%$ de glicerina+37\% CNF).

DeFrain et al. (2004) avaliaram três dietas: controle (860 g/dia de amido), baixo glicerol (430 $\mathrm{g}$ de amido+430 g de glicerol/dia) e alto glicerol (860 g/dia de glicerol) para vacas da raça Holandês no período de transição, e observaram redução no CMS no pré-parto (13,3; 10,8 e $11,3 \pm 0,50 \mathrm{~kg} / \mathrm{dia}$, respectivamente); no entanto, sem efeito no consumo pós-parto (17,9; 17,5 e 15,8 \pm 0,50 kg/dia, respectivamente) e na produção de leite $(37,2 ; 35,7$ e 34,0 kg/dia, respectivamente). Os autores concluíram que, embasados no CMS pré-parto, nas concentrações de glicose $(66,0 ; 63,1$ e 58,4 mg/dL, respectivamente) e $\beta$ hidroxibutirato (4,31; 6,18 e 5,43 mg/dL, respectivamente) no pós-parto, vacas alimentadas com os níveis de glicerol utilizados neste estudo estão mais susceptíveis a cetose.

A inclusão de glicerina em $11,5 \%$ e $10,8 \%$ no período pré e pós-parto em dietas para vacas leiteiras no período de transição, não alterou o CMS no pré (14,9 e 14,6 kg/dia) e pós-parto $(19,8$ e 20,7 kg/dia), e a produção de leite (35,6 e $37 \mathrm{~kg} /$ dia) para dieta controle $(0 \%$ de glicerol) e glicerina (99,5\% glicerol), respectivamente (CARVALHO et al., 2011). Ainda, de acordo com estes autores não foram encontradas diferenças nas concentrações de ácidos graxos não esterificados e balanço de energia, podendo a glicerina substituir o milho em dietas para vacas em período de transição. 
Boyd et al. (2013) utilizando glicerina (80-85\% glicerol) em dietas para vacas leiteiras em início de lactação, nas concentrações de $0 \mathrm{~g} /$ dia (controle), $200 \mathrm{~g} /$ dia de glicerol e $400 \mathrm{~g} / \mathrm{dia}$ de glicerol, relataram redução no CMS, com médias de 24,3; 23,1 e 23,4 kg/dia a medida que se incluiu glicerina à dieta e na produção de leite com inclusão de 400 g/dia de glicerol (37,9; 37,3 e $35.5 \mathrm{~kg} /$ dia, respectivamente para controle, 200 e $400 \mathrm{~g} /$ dia de glicerol). Este resultado contraria os observados por Boyd et al. (2011), que não verificaram diferença no CMS para vacas suplementadas com $400 \mathrm{~g} /$ dia de glicerina ( $99 \%$ de glicerol).

No Brasil, em função dos altos custos com a alimentação dos rebanhos leiteiros, diversos estudos têm buscado avaliar os efeitos da inclusão de glicerina em substituição ao milho na dieta de vacas leiteiras (Tabela 3). Zacaroni (2010) relatou redução na produção de leite de 23,4 para $21,3 \mathrm{~kg} /$ dia (controle vs glicerina) sem alterar o CMS, quando se incluiu $12,3 \%$ de glicerina bruta (76 \% glicerol) em substituição ao milho na dieta de vacas leiteiras, resultando em queda na eficiência alimentar. 
Tabela 3 - Consumo de matéria seca (CMS), produção de leite (PL) e eficiência alimentar (EA) em vacas leiteiras alimentadas com dietas contendo glicerina no Brasil.

\begin{tabular}{|c|c|c|c|c|}
\hline Fonte & Tratamento & CMS (kg/dia) & PL (kg/dia) & EA (leite/CMS) \\
\hline \multirow{2}{*}{ Zacaroni (2010) } & 0\% Glicerina & 16,8 & 23,4 & 1,40 \\
\hline & $12,3 \%$ Glicerina & 16,7 & $21,3^{*}$ & 1,30 \\
\hline \multirow{4}{*}{ San Vito (2010) } & 0\% Glicerina & 21,58 & 31,14 & 1,44 \\
\hline & 7\% Glicerina & $20,53^{*}$ & 29,77 & 1,45 \\
\hline & 14\% Glicerina & $20,41^{*}$ & $29,40 *$ & 1,44 \\
\hline & 21\% Glicerina & $20,29 *$ & $28,14^{*}$ & 1,38 \\
\hline \multirow{3}{*}{ Silva (2011) } & 0\% Glicerina & 17,0 & 19,8 & 1,16 \\
\hline & 15\% Glicerina & $16,8^{*}$ & 16,7 & 0,99 \\
\hline & 30\% Glicerina & $15,8^{*}$ & $15,4^{*}$ & 0,97 \\
\hline \multirow{4}{*}{ Costa (2011) } & Controle (cana-0\% Gli) & 16,14 & 12,27 & 0,76 \\
\hline & Cana+4\% Glicerina & 16,69 & $13,10^{*}$ & 0,78 \\
\hline & Cana+8\% Glicerina & 16,19 & $14,13^{*}$ & 0,87 \\
\hline & Cana+12\%Glicerina & 15,91 & $15,30 *$ & 0,96 \\
\hline \multirow{4}{*}{ Wilbert et al. (2013) } & 0\% Glicerina & 19,07 & 19,87 & 1,05 \\
\hline & 4\% Glicerina & 18,52 & 19,84 & 1,07 \\
\hline & 8\% Glicerina & 18,50 & 20,90 & 1,12 \\
\hline & 12\% Glicerina & 18,51 & 19,64 & 1,06 \\
\hline
\end{tabular}

*Difere dos demais tratamentos.

(COSTA, 2011; SAN VITO, 2010; SILVA, 2011; WILBERT et al., 2013; ZACARONI, 2010).

San Vito (2010) avaliando a inclusão de glicerina em substituição ao milho (0; 33,3; 66,6 e $100 \%)$, relatou redução no CMS a partir de $33,3 \%$ de substituição $(21,58$ à $20,29 \mathrm{~kg} / \mathrm{dia})$, e redução na produção de leite quando utilizou 66,6\% de substituição $(31,14$ à 28,14 kg/dia), podendo esta resposta estar relacionada a composição da glicerina utilizada (84\% glicerol e 8,64\% metanol), a qual associada a outros componentes da dieta (fontes protéicas e carboidratos) podem ter reduzido o CMS e a síntese de proteína microbiana. Desta forma, não foi possível isolar o efeito somente da glicerina neste estudo. Costa (2011) relatou que quantidades crescentes de glicerina (0, 4, 8 e 12\%) em dietas utilizando cana-de-açúcar como volumoso (80:20 volumoso:concentrado) promoveu aumento na produção de leite $(12,27$ à $15,30 \mathrm{~kg} / \mathrm{dia})$ sem afetar o CMS $(16,23 \mathrm{~kg} / \mathrm{dia})$. 
Silva (2011) avaliou quantidades crescentes de glicerina 0, 15 e 30\% da MS da dieta (86\% glicerol), e relatou tendência de redução linear no consumo de matéria seca (17,0; 16,8 e $15,8 \mathrm{~kg} /$ dia, respectivamente) e na produção de leite com médias de 19,8, 16,7 e 15,4 $\mathrm{kg} / \mathrm{dia}$, respectivamente. No entanto, Wilbert et al. (2013) ao avaliarem a inclusão de glicerina (0, 4, 8 e 12\% da MS; 81,4\% glicerol) em dietas para vacas Jersey, não observaram efeito sobre o CMS e produção de leite, podendo a glicerina substituir parcialmente o milho na dieta de vacas leiteiras sem efeitos sobre a produção e composição do leite.

\section{CONCLUSÃO}

Os efeitos da glicerina sobre CMS ainda são contraditórios, porém os resultados de desempenho produtivo têm demonstrado que este é um alimento promissor. Assim, a glicerina apresenta-se como boa alternativa alimentar, especialmente em substituição ao milho da dieta de bovinos de corte e de leite, e seu nível de inclusão deverá ser pautado principalmente em função da qualidade da mesma e de uma analise econômica detalhada de sua inclusão ou não à dieta.

Ainda, em função da qualidade variável da glicerina disponível no mercado, é necessário que além da padronização, haja um maior entendimento acerca do metabolismo ruminal da mesma, pois só assim será possível entender por quais mecanismos a glicerina altera o CMS.

\section{GLYCERIN IN CATTLE FEEDING}

\section{ABSTRACT}

$\mathrm{T}$ he increase in energy demand has been driven by the global population growth, which has led the search for new energy sources. Biofuels have been highlighted as complementary or substitute energy source, such as biodiesel, one of the most important due to some characteristics: renewable source, ecological, biodegradable, nontoxic, and free of sulfur and aromatic compounds. However, for the biodiesel industry become biological and economical feasible, it is necessary to give appropriate destination to the coproducts generated during the process. Glycerin, the main coproduct generated during the biodiesel production process has been regarded as a potential energy source for animal feeding, mainly to replace the corn grain in the diet. The inclusion of glycerin in 
ruminant diets tends to increase ruminal propionate and butyrate production, and decrease acetate, leading to a reduction in the acetate: propionate ratio and consequent increase of efficiency in using the energy from the diet. However, its $r$ influence in dry matter intake has been the major limiting factor to its inclusion in the diets for ruminants. Therefore, this revision refers to the use of glycerin in feeding and its effect on beef and dairy cattle performance.

Keywords: Biodiesel. Coproducts. Performance. Glycerol.

\section{GLICERINA EN LA ALIMENTACIÓN DEL GANADO}

\section{RESUMEN}

$\mathrm{E}$ I aumento en la demanda de energía ha sido impulsado por la creciente población mundial, lo que provocó la búsqueda de nuevas fuentes de energía. Los biocombustibles han surgido como fuente de energía complementaria o sustituto, incluyendo el biodiesel, que es de gran importancia, ya que además de ser fuente de energía renovable, es considerado ecológico, biodegradable, no tóxico, libre de azufre y compuestos aromáticos. Sin embargo, para que la producción de biodiesel sea biológicamente y económicamente viable es necesario dar destino adecuado a los subproductos generados durante el proceso de producción. La glicerina, coproducto principal generado durante la producción de biodiesel ha sido considerada como una fuente de energía potencial en la alimentación animal, en sustitución principalmente maíz. La adición de glicerina a la dieta de los rumiantes tiende a aumentar la producción ruminal de propionato y butirato, y reducir de acetato, que conduce a una reducción en la relación acetato:propionato y consiguiente aumento de la eficiencia en el uso de energía de la dieta. Sin embargo, su influencia en el consumo ha sido un importante factor limitante para su inclusión en las dietas de rumiantes. Por lo tanto, esta revisión se refiere al uso de la glicerina en la alimentación y su efecto sobre la producción en ganado carne y leche.

Palabras clave: Biodiesel. Derivados. Rendimiento. Glicerol.

\section{REFERÊNCIAS}

ABDALLA, A. L.; SILVA FILHO, J. C.; GODOI, A. R.; et al. Utilização de subprodutos da indústria de biodiesel na alimentação de ruminantes. Revista Brasileira de Zootecnia, v. 37, p. 260268, 2008.

ABUGHAZALEH, A.; ABO EL-NOR, S.; IBRAHIM, S. A. The effect of replacing corn with glycerol on ruminal bacteria in continuous culture fermenters. Journal Animal Physiology and Animal Nutrition, v. 95, p. 313-319, 2010. 
ANP. Agencia Nacional do Petróleo, Gás Natural e Biocombustíveis. Boletim mensal do biodiesel, jan. 2015. Disponível em: http://www.anp.gov.br. Acesso em: 24 de fev. 2015.

ARRUDA, P. V.; RODRIGUES, R. C. L. B.; FELIPE, M. G. A. Glicerol: um subproduto com grande capacidade industrial e metabólica. Revista Analytica, v. 26, p. 56-62, 2007.

AVILA, J. S.; CHAVES, A. V.; HERNANDEZ-CALVA, M.; et al. Effects of replacing barley grain in feedlot diets with increasing levels of glycerol on in vitro fermentation and methane production. Animal Feed Science and Technology, v. 166-167, p. 265-268, 2011.

BERGNER, H.; KIJORA, C.; CERESNAKOVA, Z.; et al. In vitro studies on glycerol transformation by rumen microorganisms. Archiv fur Tierernaehrung, v. 45, p. 245-256, 1995.

BERRY, G. Effects of feeding glycerol with different levels of non-fiber carbohydrates. College of Food, Agricultural, and Environmental Sciences, The Ohio State University, 2007. Disponível em: http://kb.osu.edu/dspace/bitstream/handle/1811/25219/Gina_Berrys_Final_Research_Rep ort.pdf?sequence= Acesso em: 07 de out. 2013.

BOYD, J.; WEST, J. W.; BERNARD, J. K. Effects of the addition of direct-fed microbials and glycerol to the diet of lactating dairy cows on milk yield and apparent efficiency of yield. Journal of Dairy Science, v. 94, p. 4616-4622, 2011.

BOYD, J.; BERNARD, J. K.; WEST, J. W. Effects of feeding different amounts of supplemental glycerol on ruminal environment and digestibility of lactating dairy cows. Journal of Dairy Science, v. 96, p. 470-476, 2013.

CARVALHO, J. R. R. Desempenho, características de carcaças e qualidade da carne de tourinhos alimentados com diferentes níveis de glicerina bruta. Lavras: UFLA, 2011, 134p. Dissertação (Mestrado em Zootecnia), Universidade Federal de Lavras, 2011.

CARVALHO, E. R.; SCHMELZ-ROBERTS, N. S.; WHITE, H. M. Replacing corn with glycerol in diets for transition dairy cows. Journal of Dairy Science, v. 94, p. 908-916, 2011.

CEPEA. Centro de Estudos Avançados em Economia Aplicada - Esalq/USP. Boletim do Leite, jan. 2015. Disponível em: http://cepea.esalq.usp.br/. Acesso em: 03 de mar. 2015.

COSTA, L. T. Glicerina bruta na dieta de vacas lactantes confinadas. Itapetinga: UESB, 2011, 64p. Tese (Doutorado em Zootecnia), Programa de Pós-graduação em Zootecnia, Universidade Estadual do Sudoeste da Bahia, 2011. 
D'AUREA, A. P. Glicerina, resíduo da produção de biodiesel, na terminação de novilhas da raça Nelore. Jaboticabal: UNESP, 2010, 59p. Dissertação (Mestrado em Zootecnia) Faculdade de Ciências Agrárias e Veterinárias, Universidade Estadual Paulista, 2010.

DASARI, M. A. P.; KIATSIMKUL, P. P.; SUTTERLIN, W. R.; et al. Low pressure hydrogenolysis of glycerol to propylene glycol. Applied Catalysis A: General, v. 281, n. 1-2, p. 225-231, 2005.

DEFRAIN, J. M.; HIPPEN, A. R.; KALSCHEUR, K. F.; et al. Feeding Glycerol to Transition Dairy Cows: Effects on Blood Metabolites and Lactation Performance. Journal of Dairy Science, $v$. 87, p. 4195-4206, 2004.

DONKIN, S. S. Glycerol from biodiesel production: the new corn for dairy cattle. Revista Brasileira de Zootecnia, v. 37, p. 280-286, 2008.

DONKIN, S. S.; KOSER, S. L.; WHITE, H. M.; et al. Feeding value of glycerol as a replacement for corn grain in rations fed to lactating dairy cows. Journal of Dairy Science, v. 92, p. 51115119, 2009.

ENCIMAR, J. M.; GONZALEZ, J. F.; RODRÍGUEZ, J. J.; et al. Biodiesel fuels from vegetable oils: transesterification of Cynara cardunculus L. oils with ethanol. Energy \& Fuels, v. 16, p. 443450, 2002.

FÁVARO, V. R. Utilização de glicerina, subproduto do biodiesel, na alimentação de bovinos. Jaboticabal: UNESP, 2010, 59p. Dissertação (Mestrado em Zootecnia), Faculdade de Ciências Agrárias e Veterinárias, Universidade Estadual Paulista, 2010.

FDA. Food and Drug Administration. Code of Federal Regulations, 21CFR582.1320, título 21, v. 62014.

FISHER, L. J.; ERFLE, J. D.; LODGE, G. A.; et al. Effects of propylene glycol or glycerol supplementation of the diet of dairy cows on feed intake, milk yield and composition, and incidence of ketosis. Canadian Journal Animal Science, v. 53, p. 289-296, 1973.

GUNN, P. J.; LEMENAGER, R. P.; BUCKMASTER, D. R.; et al. Effects of destillers dried grains with solubles and crude glycerin on performance, carcass characteristics, and metabolic parameters of early weaned beef calves. The Professional Animal Science, v. 27, p. 283-294, 2011.

HOBSON, P. N.; MANN, S. C. The isolation of glycerol-fermenting and lipolytic bacteria from the rumen of the sheep. Journal General Microbiology, v. 25, p. 227-240, 1961.

JOHNSON, R. B. The treatment of ketosis with glycerol and propylene glycol. Cornell Veterinarian, v. 44, p. 6-21, 1954. 
JOHNSON, K. A.; JOHNSON, D. E. Methane emissions from cattle. Journal of Animal Science, v. 73, p. 2483-2492, 1995.

KERR, B. J.; WEBER, T. E.; DOZIER III, W. A.; et al. Digestible and metabolizable energy content of crude glycerin originating from different sources in nursery pigs. Journal of Animal Science, v. 87, p. 4042-4049, 2009.

KREBS, H. A.; LUND, P. Formation of glucose from hexoses, pentoses, polyols and related substances in kidney cortex. Biochemistry Journal, v. 98, p. 210- 214, 1966.

KREHBIEL, C. R. Ruminal and physiological metabolism of glycerin. In: SYMPOSIUM: RUMINANT NUTRITION: GLYCERIN AS A FEED FOR RUMINANTS. 2008, Indianapolis. Abstracts. Disponível em: http://www.jtmtg.org/JAM/2008/abstracts/2008-JAMAbstracts.pdf. 2008, n. 489, p. 392.

LEÃO, J. P.; RAMOS, A. T.; MARUO, V. M. Anatomopatologia de amostras de bovinos alimentados com glicerol. Ciência Rural, v. 42, p. 1253-1256, 2012.

LEE, S. Y.; LEE, S. M.; CHO, Y. B.; et al. Glycerol as a feed supplement for ruminants: In vitro fermentation characteristics and methane production. Animal Feed Science and Technology, v. 166-167, p. 269-274, 2011.

LENG, R. A. Glucose synthesis in ruminants. Advances in Veterinary Science and Comparative Medicine, v. 14, p. 241-242, 1970.

LING, J. R.; ARMSTEAD, I. P. The in vitro uptake and metabolism of peptides and amino acids by five species of rumen bacteria. Journal of Applied Bacteriology, v. 78, p. 116-124, 1995.

$\mathrm{MACH}, \mathrm{N}$.; BACH, A.; DEVANT, M. Effects of crude glycerin supplementation on performance and meat quality of Holstein bulls fed high-concentrate diets. Journal of Animal Science, $v$. 87, p. 632-638, 2009.

MOTA, C. J. A.; SILVA, C. X. A.; GONÇALVES, V. L. C. Gliceroquímica: Novos produtos e processos a partir da glicerina de produção de biodiesel. Química Nova, v. 32, n. 3, p. 639648. 2009.

OLIVEIRA, A. S.; OLIVEIRA, M. R. C.; SOUZA, J. G.; et al. Perspectivas na utilização de coprodutos do biodiesel na produção de bovinos de corte. In: SIMPÓSIO MATOGROSSENSE DE BOVINOCULTURA DE CORTE, 1, 2011, Cuiabá. Anais.Cuiabá, 2011, p. 131-150.

OLIVEIRA, J. S.; ANTONIASSI, R.; FREITAS, S. C. Composição química da glicerina produzida por usinas de biodiesel no Brasil e potencial de uso na alimentação animal. Ciência Rural, v. 43, p. 509-512, 2013. 
PAGGI, R. A.; FAY, J. P.; FERNANDEZ, H. M. Effect of short-chain acids and glycerol on the proteolytic activity of rumen fluid. Animal Feed Science and Technology, v. 78, p. 341-347, 1999.

PAGGI, R. A.; FAY, J. P.; FAVERIN, C. In vitro ruminal digestibility of oat hay and cellulolytic activity in the presence of increasing concentrations of short-chain acids and glycerol. Journal of Agricultural Science, v. 142, p. 89-96, 2004.

PARSONS, G. L.; SHELOR, M. K.; DROUILLARD, J. S. Perfomance and carcass traits of finishing heifers fed crude glycerin. Journal of Animal Science, v. 87, p. 653-657, 2009.

PASCHOALOTO, J. R. Glicerina associada a volumosos na dieta de bovinos. Jaboticabal: UNESP, 2012, 58p. Dissertação (Mestrado em Zootecnia). Faculdade de Ciências Agrárias e Veterinárias, Universidade Estadual Paulista, 2012.

PLÁ, J. A. Perspectivas do biodiesel no Brasil. Indicadores Econômicos FEE, v. 30, n. 2, p. 179190, 2002.

REMOND, B.; SOUDAY, E.; JOUANY, J. P. In vitro and In vivo fermentation of glycerol by rumen microbes. Animal Feed Science and Technology, v. 41, p. 121-132, 1993.

RICO, D. E.; CHUNG, Y. H.; MARTINEZ, C. M.; et al. Effects of partially replacing dietary starch with dry glycerol in a lactating cow diet on ruminal fermentation during continuous culture. Journal of Dairy Science, v. 95, p. 3310-3317, 2012.

ROGER, V., FONTY, G.; ANDRE, C.; et al. Effects of glycerol on the growth, adhesion, and cellulolytic activity of rumen cellulolytic bacteria and anaerobic fungi. Current Microbiology, v. 25, p. 197-201, 1992.

RUSSELL, J. B. Predominant ruminal bacteria and archaea. In: RUSSELL, J. B. (Ed.). Rumen Microbiology and its Role in Ruminant Nutrition. Ithaca: Cornell University Press, 2002, p. 18-24.

SAN VITO, E. Glicerina bruta na alimentação de vacas leiteiras. Viçosa: UFV, 2010, 40p. Dissertação (Mestrado em Zootecnia), Programa de Pós-graduação em Zootecnia, Universidade Federal de Viçosa, 2010.

SANTOS, P. P.; ABDALLA, A. L.; BERENCHTEIN, B.; et al. Produção de gases e degradabilidade in vitro de farelo de algodão e glicerina bruta em substituição ao farelo de soja e ao milho em dietas para ruminantes. In: REUNIÃO ANUAL DA SOCIEDADE BRASILEIRA DE ZOOTECNIA, 48, 2011, Belém. Anais. Belém. 2011.

SCHRÖDER, A.; SÜDEKUM, K. H. Glycerol as a by-product of biodiesel production in diets for ruminants. In: INTERNATIONAL RAPESEED CONGRESS, 10, 1999, Canberra. Proceedings. Canberra: Regional Institute. 1999. 
SILVA, Z. F. Digestão e fermentação ruminal em vacas leiteiras recebendo glicerina bruta na dieta. Jaboticabal: UNESP, 2011, 56p. Tese (Doutorado em Zootecnia). Faculdade de Ciências Agrárias e Veterinárias, Universidade Estadual Paulista, 2011.

SOUZA, C. A. Sistemas catalíticos na produção de biodiesel por meio de óleo residual. In: CONGRESSO INTERNACIONAL SOBRE GERAÇÃO DISTRIBUÍDA E ENERGIA NO MEIO RURAL, 6, 2006, Campinas. Anais. Campinas: Ed. da UEC, 2006.

STORCK BIODIESEL. O que é o biodiesel? Curitiba. Maio 2008. Disponível em: http://www.storck.com.br/index-destques2.htm. Acesso em: 07 jan. 2012.

STRADIOTTI JÚNIOR, D.; QUEIROZ, A. C.; LANA, R. P.; et al. Ação do extrato de própolis sobre a fermentação in vitro de diferentes alimentos pela técnica de produção de gases. Revista Brasileira de Zootecnia, v. 33, p. 1093-1099, 2004.

TAJIMA, K.; AMINOV, R. I.; NAGAMINE, T. Diet-dependent shifts in the bacterial population of the rumen revealed with real-time PCR. Applied Enviromental Microbiology, v. 67, p. 2766-2774, 2001.

TERRÉ, M.; NUDDA, A.; CASADO, P. The use of glycerine in rations for light lamb during the fattening period. Animal Feed Science and Technology, v. 164, p. 262-267, 2011.

TOSETTO, M. G.; ANDRIETTA, S. R. Cinética de produção de glicerol em processo de fermentação alcoólica utilizando diferentes matérias primas industriais. In: SIMPÓSIO NACIONAL DE FERMENTAÇÕES, 14, 2003, Florianópolis. Anais. CDROM, 2003.

TRABUE, S.; KENWOOD, S.; TJANDRAKUSUMA, S.; et al. Ruminal fermentation of propylene glycol and glycerol. Journal of Agriculture and Food Chemistry, v. 55, p. 7043-7051, 2007.

UNIVERSIDADE DE AÇORES. Laboratório de Ambiente Marinho e Tecnologia. Energias Renováveis-Biocombustíveis, 2008. Disponível em: www.lamtecid.com/energias/biocombustiveis.php. Acesso em 30 de set. 2013.

VAN CLEEF, E. H. C. B. Glicerina bruta em dietas para bovinos da raça Nelore confinados. Jaboticabal: UNESP, 2012, 129p. Tese (Doutorado em Zootecnia). Faculdade de Ciências Agrárias e Veterinárias, Universidade Estadual Paulista, 2012.

VAN CLEEF, E. H. C. B.; EZEQUIEL, J. M. B.; D’AUREA, A. P.; et al. Crude glycerin in diets for feedlot Nellore cattle. Revista Brasileira de Zootecnia, v. 43, p. 86-91, 2014.

VISCARDI, F. A. P. D. Análise de variabilidade técnica e econômica do biodiesel no Brasil. In: CONGRESSO BRASILEIRO DE P\&D EM PETRÓLEO E GÁS, 3, 2005, Salvador. Anais. Salvador, 2005. 
WANG, C.; LIU, Q.; HUO, W. J.; et al. Effects of glycerol on rumen fermentation, urinary excretion of purine derivatives and feed digestibility in steers. Livestock Science, v. 121, p. 15-20, 2009.

WILBERT, C. A.; PRATES, E. R.; BARCELLOS, J. O. J.; et al. Crude glycerin as an alternative energy feedstuff for dairy cows. Animal Feed Science and Thechnology, v. 183, p. 116-123, 2013.

ZACARONI, O. F. Resposta de vacas leiteiras à substituição de milho por glicerina bruta. Lavras: UFLA, 2010. 43p. Dissertação (Mestrado em Veterinária), Programa de PósGraduação em Ciências Veterinárias, Universidade Federal de Lavras, 2010.

Autor para correspondência: Pablo Gomes de Paiva. Av. Duque de Caxias Norte, 225-Campus da USP. CEP: 13635-900, Pirassununga-SP. pagppaiva@gmail.com 